\title{
THOMAS REID, 0 MÉTODO DE FILOSOFAR E A REJEIÇÃO DO CETICISMO
}

\author{
Roberto Hofmeister Pich \\ PUCRS/CNPq
}

\begin{abstract}
In this study we attempt to describe and to analyze an aspect of Thomas Reid's $(1710-1796)$ criticism to skepticism. Substantially, the core of this atittude is his criticism to "the common theory of ideas". A less explored part of his arguments, one that is the background of them, is Reid's conception of the method of obtaining philosophical truths. One decisive aspect here is the reflection about adopting certain "rules of philosophising" according to Reid. The relevance of studing the concept of philosophical method in Reid can be shown by remembering that, in the whole construction of his theory about the sources of knowledge and the principles of common sense, the "rules" are apllied in a rigorous and uniform way. His method helps one to understand, moreover, the kind of rejection of skepticism in epistemology that Reid will be able to accomplish.
\end{abstract}

Keywords: Thomas Reid, skepticism, theory of ideas, scientific knowledge, method of philosophy.

Resumo: 0 presente estudo tem o propósito de descrever e analisar um elemento da crítica de Thomas Reid (1710-1796) ao ceticismo. Em boa medida, o cerne dessa é a sua crítica à "teoria geral das ideias". Uma parte menos explorada dessa crítica, e que é o seu pano de fundo, é a concepção reidiana sobre o método de obtenção das verdades filosóficas. Aqui, um item central é a reflexão sobre a adoção de certas "regras do filosofiar" de acordo com Reid. A relevância do estudo da concepção do método filosófico, em Reid, pode ser apontada ao lembrar que, em toda a construção de sua teoria sobre as fontes de conhecimento e os princípios do senso comum, as "regras" são rigorosa e universalmente aplicadas. O seu método possibilita entender, ademais, o tipo de rejeição do ceticismo epistemológico que Reid poderá construir.

Palavras-chave: Thomas Reid, ceticismo, teoria das ideias, conhecimento científico, método da filosofia. 


\section{Introdução: ceticismo e "teoria comum das ideias"}

Não há dúvidas de que Thomas Reid (1710-1796), o grande pensador do "Iluminismo escocês" em filosofia, viu na rejeição da "teoria comum das ideias" (common theory of ideas) um elemento central de sua resposta ao ceticismo. Apesar disso, dificilmente é correto o parecer de que o sucesso da recusa reidiana à teoria das ideias basta como uma resposta ao ceticismo, sobretudo como ele é representado pelos principais interlocutores de Reid, a saber, George Berkeley e David Hume. Nesse sentido, GRECO exige, a meu juízo com razão, que se somem à (a) rejeição reidiana da teoria das ideias (b) a teoria reidiana da percepção, (c) a teoria da evidência, por Reid, e (d) a sua "metodologia"1.

O primeiro ponto tem contornos famosos. Ora, uma resposta bemsucedida ao ceticismo teria de passar por uma recusa à "teoria da ideias" como condição necessária, portanto -, porque, segundo Reid, a teoria das ideias gera resultados céticos não apenas sérios, mas eventualmente incontornáveis ${ }^{2}$. A tese básica, e característica, da "teoria comum das ideias" é que o objeto imediato da mente é uma ideia na mente. Em particular, para o conhecimento perceptual e, pois, "do mundo exterior", isso traz a consequência de que não se percebe imediatamente um objeto "exterior", mas só mediatamente, dado que só uma "ideia" (idea) é um objeto imediato de uma operação mental qualquer. Independentemente de ser tomada como "imagem", "impressão" ou "sensação" representada, na mente, certo é que uma "ideia" é entendida por Reid como um meio representativo, diferente ele mesmo de um ato de pensar. Reid acredita que a teoria epistêmica que adota a existência e a função de "ideias", nesses termos, é "comum" justamente porque ela é admitida de modo praticamente universal pelos filósofos ${ }^{3}$.

GRECO ofereceu contornos bem precisos às consequências céticas da teoria comum, ao enfatizar o uso de premissas expressivas da teoria, em

\footnotetext{
${ }^{1}$ Cf. John Greco, Reid's Reply to the Skeptic, in: Terence Cuneo and René Van Woudenberg (eds.), The Cambridge Companion to Thomas Reid, p. 134. Cf. também Yves Michaud, Reid's Attack on the Theory of Ideas: From a Reconsideration of Reid's Arguments to a Reassessment of the Theory of Ideas, in: Melvin and Eric Matthews (eds.), The Philosophy of Thomas Reid, p. 14ss.

${ }^{2}$ Cf. EIP II.viii.126; II.xi.156ss. Cf. também IHM II.vi.33.

3 Cf. Essays on the Intellectual Powers of Man (a partir daqui EIP) I.i.31s.; EIP II.vii.105ss.; EIP II.viii.112ss.
} 
argumentos oriundos de autores como Berkeley e Locke. Assim, aquilo que GRECO chamou de argumento de que "não há nenhuma concepção possível” (no possible conception), oriundo de Berkeley ${ }^{4}$, tem como primeira premissa que "(1) Não podemos ter concepção de nada, mas só do que se parece com alguma sensação ou ideia na nossa mente” - e concluirá que “(5) Não podemos ter nem evidência nem conhecimento de substâncias

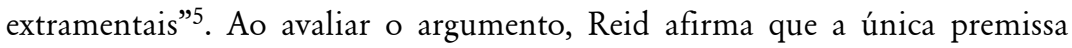
questionável é a que expressa a teoria das ideias, a saber a premissa (1). Por semelhante modo, aquilo que GRECO chamou de argumento de que "não há nenhum objeto mediato" exibe também uma premissa marcante da teoria das ideias e que Reid encontra em Locke - novamente atingindo, contra a intenção original de Locke, uma conclusão cética ${ }^{6}$. Afinal, dada a premissa “(1) Não podemos ter nenhum objeto imediato de pensamento senão as nossas próprias ideias”, pode-se atingir, supostas outras premissas, a conclusão de que "(6) Não podemos ter nenhum conhecimento de objetos exteriores”. Nesse argumento, Reid também entenderia que a única premissa questionável vem a ser a primeira premissa ${ }^{7}$.

Em diversas passagens, Reid afirma que a teoria das ideias é, não exatamente refutável em suas conclusões, mas equivocada em seu enunciado. Não há ideias, como supostas na teoria, e ideias não têm força explicativa quanto ao conhecimento. As duas críticas se ligam diretamente aos critérios do método filosófico e à concepção de filosofia que Reid adota. De acordo com Reid, a "teoria comum das ideias" fracassa flagrantemente nos dois testes newtonianos e baconianos: (i) não há evidência ou indício para mostrar que as ideias, como concebidas pela teoria comum das ideias, são um

\footnotetext{
${ }^{4}$ A fonte para o mesmo, de acordo com John Greco (cf. a nota seguinte), seria An Inquiry into the Human Mind on the Principles of Common Sense, (a partir daqui IHM) V.viii.74-75.

${ }^{5}$ Cf. John Greco, Reid's Reply to the Skeptic, in: Terence Cuneo and René Van Woudenberg (eds.), op. cit., p. 136.

${ }^{6} \mathrm{~A}$ fonte para o mesmo, de acordo com John Greco (cf. a nota seguinte), seria EIP VI.iii.437.

${ }^{7}$ Cf. John Greco, Reid's Reply to the Skeptic, in: Terence Cuneo and René Van Woudenberg (eds.), op. cit., p. 137-138. Por sua vez, ao propor como o "Princípio da Crença" do cético sobre o mundo exterior que Reid tem em mente a proposição "É errado crer na proposição $p$ a menos que $p$ "esteja fundada em uma razão"', em que a última parte significa "possa ser provada por raciocínio", René van Woudenberg, Reid and Kant against the Sceptic, in: Joseph Houston (ed.), Thomas Reid. Context, Influence and Significance, p. 163ss., também enfatiza que uma das críticas que Thomas Reid fará ao cético será mostrar que esse princípio se associa a uma "teoria da mente" problemática, a saber, "the Way of Ideas". ${ }^{8}$ Cf., em especial, EIP II.viii.121.
} 
fato ou existem em realidade; além disso, (ii) mesmo se as ideias como ali concebidas existissem, elas não explicariam os fenômenos que supostamente explicam. Com respeito a todas as formas de bom desempenho epistêmico, a partir das as fontes não-falaciosas de conhecimento, Reid mantém de forma rigorosa e consistente essas duas convicções. No que consistem elas, mais detalhadamente? De forma sucinta, quais consequências são adequadamente anotadas acerca da realidade das ideias, caso se admita os dois critérios dados? Se a última pergunta terá réplica breve nas Observações Finais deste estudo, cabe, a seguir, construir uma resposta bem articulada à primeira pergunta, através da (1) exposição das regras do filosofar, da (2) indicação (parcial) do entendimento de Reid sobre a filosofia como disciplina e da (3) visão de sua distinção severa entre conjetura e indução, que deve expressar a adoção de uma racionalidade teórica que parece apta ao senso comum.

\section{Regulae philosophandi}

De forma explícita já no Inquiry into the Human Mind (1764), porém de forma reiterada, explicada e expandida nos Essays on the Intellectual Powers of Man (1785) 9 , Reid revela a sua inteira convicção de que todo conhecimento, simples ou teoricamente complexo, para que se legitime como tal, é - ao menos parcialmente - resultado de uma metodologia, aplicada por Isaac Newton (1642/1643-1727) e inspirada em Francis Bacon (1561-1626), chamada por Newton e repetida por Reid como "regulae philosophandi”. No Inquiry, Reid afirma que as regras são "máximas do senso comum" e praticadas "todos os dias na vida comum" e, nesses termos, pode-se presumir, ou bem são ou estão sob os "princípios do senso comum" - o que significa que são confirmadas ${ }^{10}$ e, até certo ponto, dependentes deles e, pois, consistentes com eles (cf. abaixo). Ali, Reid afirmava que só o filosofar por

\footnotetext{
${ }^{9}$ Essas, porém muito mais essencialmente a segunda, são as duas fontes básicas da obra de Reid utilizadas neste ensaio.

${ }^{10}$ Creio que há também um sentido em que se pode dizer que elas confirmam os princípios do senso comum, uma vez que permitem chegar a eles como justas generalizações a partir de observações evidentes acerca da mente. De todo modo, não considero os primeiros princípios do senso comum rigorosamente como parte do método "científico" ou mais simplesmente das "regras", dado que, salvo melhor entendimento, eles não são exatamente princípios de desoberta ou de obtenção de verdades, mas, antes, como que condições de possibilidade - ou princípios "transcendentais" - de todo uso da razão.
} 
meio dessas regras previne o erro quanto ao "sistema material" e quanto "à mente"11. Em uma nota explicativa, os editores do Inquiry lembram que a adoção das regras por Reid ocorreu precocemente, isto é, a mais antiga afirmação sobre as mesmas consta em notas de um aluno, feitas a partir das preleções de Reid, no período acadêmico de 1757-1758, no King's College ${ }^{12}$ :

\begin{abstract}
"Primeira Regra. Não devem ser admitidas mais causas para coisas naturais do que as que são tanto verdadeiras quanto suficientes para explicar os seus fenômenos. Segunda Regra. Efeitos semelhantes têm a mesma causa ou causas semelhantes... Terceira Regra. Essas qualidades de Corpos que não podem ser aumentadas ou diminuídas, e têm concordância em todos os corpos, sobre as quais experimentos foram feitos, devem ser reconhecidas como qualidades de [todos os] corpos, sejam quais forem. Pois, as qualidades dos corpos não são conhecidas senão por experimentos, e portanto tantas devem ser consideradas gerais quantas em geral têm concordância com experimentos. Quarta Regra. Na filosofia experimental, proposições coletadas a partir de fenômenos, por indução, devem ser julgadas, não obstante hipótese contrária, ou acuradas ou muito aproximadamente verdadeiras, até que outros fenômenos ocorram, pelos quais elas possam ser tornadas mais acuradas ou menos passíveis de exceções". (AUL MS K.160,8).
\end{abstract}

Os escritos principais de Reid sobre a mente e o conhecimento (IHM e EIP) revelam, de forma inequívoca, que Newton teve grande presença na formação intelectual de Reid, o qual, efetivamente, conhecia muito bem a física newtoniana e, com notável frequência, alude a itens da lei da gravitação

\footnotetext{
${ }^{11} \mathrm{Cf}$. IHM I.i.12.

${ }^{12}$ Cf. Derek R. Brookes, Explanatory Notes, in: Thomas Reid, An Inquiry into the Human Mind on the Principles of Common Sense, p. 220. A citação que segue é feita a partir daí. De resto, tanto o elogio como a adoção implícita ao método baconiano-newtoniano do filosofar podem ser lidos em especial nas ora Orações I e II, de Reid, respectivamente proferidas, originalmente em latim, nos anos de 1753 e 1756; cf. Thomas Reid, The Philosophical Orations of Thomas Reid, Oration I, p. 35ss.; Oration II, p. 45s., 49s. Cf. ainda D. D. Todd, Introduction, in: Thomas Reid, The Philosophical Orations of Thomas Reid, p. 14-16.
} 
dos corpos e das propriedades da luz ${ }^{13}$. Para todos os efeitos, BROADIE enfatiza que o herói de Reid, no que tange à sustentação teórica de uma metodologia científica, é Francis Bacon - Isaac Newton é referido como aquele que, não tendo inventado a "verdadeira metodologia científica", aplicou-a com enorme sucesso ${ }^{14}$. Mais detalhadamente, no entanto, quais são os aspectos centrais das "regras"?

Em contextos diversos, Newton é referido por Reid como aquele que apontou "claramente o caminho ao conhecimento das obras da Natureza". Isso significou uma adesão, por Newton, ao ensino de Bacon sobre desprezar as "hipóteses" como "ficções da fantasia humana"15. Ora, em primeiro lugar, Bacon pôs como "regra do filosofar" que como causas das coisas da natureza só podem ser assinaladas aquelas que "podem ser provadas ter existência real”. Isso primeiramente significa constatar indícios ou ter evidência de causas-fenômenos - de forma a "provar toda opinião pela regra do fato e da experiência", em que "fatos" devem ser observados de forma "devida" ou "suficientemente atestado" 16 . Explicar fenômenos constatados é o mesmo que descobrir "leis da natureza", aquelas que dizem como ou por que os mesmos fenômenos são produzidos. Assim, o primeiro critério ou a primeira regra do filosofiar, em suma, "o verdadeiro método de filosofar" é resumido do seguinte modo: "a partir de fatos reais verificados pela observação e pelo experimento [deve-se] coletar pela justa indução as leis da Natureza, e apliar as leis assim descobertas para explicar os fenômenos da Natureza"17. Desse modo, pois, a aquisição de conhecimentos é estruturada (i) pela observação e pelo experimento, o que indica a confiança assumida, no método, no próprio poder de observar e, nesse passo, a adoção presumida de um empirismo, (ii)

\footnotetext{
${ }^{13}$ Cf. EIP II.iii.78s.; II.xvii.200-201; II.xviii.215ss. Para todos os detalhes, cf. a bela biografia intelectual de Thomas Reid escrita por Alexander Broadie, Reid in context, in: Terence Cuneo and René Van Woudenberg (eds.), The Cambridge Companion to Thomas Reid, p. 31-52. Em um registro biográfico, cabe lembrar que a mãe de Reid, Margaret Gregory, provinha de uma família escocesa com muitos casos de talentos científicos. Assim, pois, David Gregory, tio de Reid por parte da mãe, foi "Savilian Professor" de astronomia, em Oxford, e amigo próximo de Sir Isaac Newton.

${ }^{14} \mathrm{Cf}$. Alexander Broadie, Reid in context, in: Terence Cuneo and René Van Woudenberg (eds.), op. cit., p. 38-40. Cf. também EIP I.iii.51-52.

${ }^{15}$ Cf., por exemplo, EIP.viii.121: "Perseguindo esse caminho sem desvios, NEWTON descobriu as leis de nosso sistema planetário e dos raios de luz, e deu os primeiros e mais nobres exemplos daquela casta indução que Lord BACON pôde somente delinear em teoria".

${ }^{16} \mathrm{Cf}$. EIP I.iii.51.

${ }^{17}$ Cf. EIP II.viii.121.
} 
pela indução enumerativa ou "justa", com o que Reid tem em vista a "generalização" a partir de amostras suficientes, repetidas e em tese inequívocas, e finalmente (iii) a aplicação dessa mesma generalização, como lei, aos casos particulares, explicando-os ${ }^{18}$.

Não há qualquer dúvida de que Reid acredita que esse procedimento é de senso comum, isto é, é obediente ao mecanismo cognitivo natural ou aos princípios constitutivos (sempre "pressupostos") de como seres humanos obtêm crenças sobre o mundo ${ }^{19}$; na esteira disso, esse procedimento descreve a maneira como, segundo e sobre a natureza, e da única forma justificada, crenças são adquiridas. Por esse motivo, Reid pode dizer que essas regras, para o filósofo da natureza, são regras fixadas com certeza não menor do que seriam aquelas que servem ao matemático. Pode ser afirmado, assim, que aquele que investiga o mundo consegue obter "evidência" sobre "lei[s] da natureza a partir de indução", uma evidência que não é de tipo demonstrativo, mas antes um "tipo de evidência sobre a qual as mais importantes questões da vida humana devem repousar" 20 .

Em várias passagens, em especial em passagens do Ensaio I ou "Preliminar", em que os diversos aspectos de concepção e método em ciências e filosofia são previamente expostos por Reid, a segunda regra, como é dita nos demais Ensaios, aparece conjugada diretamente com a "primeira regra do filosofar" estabelecida por Newton nos Princípios matemáticos da filosofia natural - "regra de ouro" e teste do que é sólido e do que não é sólido em filosofia. O segundo critério reza que as causas de efeitos naturais

\footnotetext{
18 Também no campo da lógica, dado o seu convencimento de que a ciência sobre o mundo material e 0 mundo mental é a meta absoluta do empreendimento intelectual, Reid fez contribuições interessantes, na esteira da crítica de Bacon - et alii, como George Campbell - à lógica silogística tradicional. Ela era de pouco uso para investigar a natureza. A partir sua obra A brief account of Aristotle's logic, with remarks [Um breve relato da lógica aristotélica, com observações], escrita entre os anos de 1767 e 1773, por sugestão de Lord Kames, Reid argumentou a favor da relevância da lógica indutiva no campo da ciência, no sentido de ser ela a lógica apta a estabelecer conclusões verdadeiras e aceitáveis sobre descobertas no mundo. Em vez de uma lógica de desdobramento de conteúdos essenciais contidos nas premissas, cabia promover uma lógica que mostrasse o progresso no conhecimento, enquanto procede desde os casos individuais mais certos e promove o justo ascenso a princípios gerais prováveis e menos certos. Cf. sobre isso Alexander Broadie, Reid in Context, in: Terence Cuneo and René Van Woudenberg (eds.), op. cit., p. 44-47.

${ }^{19} \mathrm{Cf}$. EIP I.ii.39ss. Sobre o debate em torno dos "primeiros princípios do senso comum" como "princípios constitutivos", cf., por exemplo, Patrick Rysiew, Reid and Epistemic Naturalism, in: John Haldane and Stephen Read (eds.), The Philosophy of Thomas Reid - A Collection of Essays, p. 36ss.

${ }^{20}$ Cf. EIP II.viii.121.
} 
admitidas têm de se mostrar "suficientes para explicar os seus fenômenos"21. Assim, pois, em um capítulo importante porque de aplicação das regulae philosophandi, a saber, "Hipóteses acerca de nervos e cérebro"22, em que a propósito conjeturas de anatomia do "mental", pelo Dr. Briggs, são testadas (e desqualificadas), Reid explana aquela segunda regra ou "condição" exigida por Newton como exigindo das causas das coisas da natureza "assinaladas pelos Filósofos" que elas "sejam suficientes para explicar os fenômenos"23. Embora nos contextos diretos da listagem dessas regras os comentários sobre a segunda sejam modestos, um breve ensaio de sua importante aplicação poderá ser conferido mais abaixo (cf. as Considerações Finais). Antes disso, porém, pode-se notar que, se as condições (i) e (ii) são necessárias dificilmente suficientes - para justificar alegações imediatas e/ou mediatas (por argumento) de conhecimento do mundo e da mente, a condição (i), a "condição de verdade", é uma condição necessária para a condição (ii), a "condição de suficiência"24. Assim afirma Reid: "Se a causa assinalada realmente existe, considere, em seguida, se o efeito para cuja explicação ela é trazida necessariamente segue-se a partir dela. A menos que ela tenha essas duas condições, ela não serve para nada" 25 . Ora, sem o indício ou a evidência de existência, a condição (ii) nem sequer é considerada. E de fato o efeito que uma causa indicada deve explicar só pode ser estabelecido como tal, presumese, por justa indução, isto é, a partir da reiterada, adequada e suficiente observação, bem como da generalização do processo - da afirmação de um processo nomológico. Na passagem, Thomas Reid assevera que o efeito deve seguir-se "necessariamente" a partir da sua causa. É preciso observar e argumentar, portanto, que a generalização à qual se pode chegar realmente se

\footnotetext{
${ }^{21}$ Cf. EIP I.iii.51: "A primeira regra do filosofar estabelecida pelo grande Newton é essa: Causas rerum naturalium, non plures admitti debere, quam quae et verae sint, et earum phaenominis explicandis sufficiant".

22 Cf. EIP II.iii.76-87.

${ }^{23}$ Cf. EIP II.iii.83.

${ }^{24}$ Cf. Alan Tapper, Reid and Priestley on Method and the Mind, in: John Haldane and Stephen Read (eds.), The Philosophy of Thomas Reid - A Collection of Essays, p. 103: "Os heróis de Reid, Bacon, e em seguimento a ele, Newon, mostraram que explicações são válidas somente se tanto a condição de verdade quando a condição de suficiência são satisfeitas. Ficando a condição de suficiência por si mesma, a explicação se torna uma questão de invenção engenhosa. A condição de verdade crucialmente fundamenta a explicação no testemunho dos sentidos".

${ }^{25}$ Cf. EIP I.iii.51.
} 
revela capaz de explicar que, em se dando determinada causa, dá-se determinado efeito.

\section{Anatomia da mente}

Notável, e ao mesmo tempo óbvio ao leitor, é que a intenção de aplicação, por Reid, das regras ou condições do verdadeiro filosofar é conhecer a mente, não conhecer a natureza qua sistema material. Anunciando a rejeição radical que Reid fará das hipóteses e conjeturas no sistema real de conhecimento (ver abaixo), pode-se aludir à seguinte sentença peremptória: "Uma interpretação justa da natureza é a única filosofia sã e ortodoxa: tudo o que adicionamos de nós mesmos é apócrifo e de nenhuma autoridade" 26 . Ocorre que interpretar a natureza, para Reid, é também interpretar a mente, pois a mente não só é parte da "natureza", a sua parte mental, como também é investigável de maneira justa por aquelas mesmas regras. De modo geral, pois, segundo Reid a "filosofia da natureza" é a investigação do "sistema material", e a "filosofia da mente" (philosophy of mind) é a investigação do sistema mental. Seguindo as regras do filosofar e os ditames do senso comum, a filosofia da mente, e nisso derivativamente a teoria do conhecimento qua teoria de nossa natureza cognitiva nãofalaciosa ${ }^{27}$, é uma "ciência". E Reid expõe claramente o que se pode descobrir cientificamente da mente: "Tudo o que sabemos do corpo é devido à dissecação anatômica e à observação, e deve ser por uma anatomia da mente que podemos descobrir os seus poderes e princípios" 28 .

$\mathrm{Na}$ literatura, a metodologia baconiana-newtoniana assumida por Reid para investigar a natureza e o sistema mental por derivação tem sido inserida no assim chamado "naturalismo providencial" (providential naturalism), já

\footnotetext{
${ }^{26} \mathrm{Cf}$. IHM I.i.12.

${ }^{27}$ Não se está assumindo, aqui, uma equivalência entre a ciência da mente e a teoria do conhecimento; sendo a primeira o relato descritivo e reflexivo a partir de um método de estudo do sistema mental e a segunda, contando com uma abordagem dos "primeiros princípios do senso comum", uma articulação de como podem ser justificadas as diversas crenças verdadeiras das diversas fontes doxásticas da mente, sobretudo diante do parecer do cético, ciência da mente e filosofia científica seriam plenamente complementares; cf. também Roger D. Gallie, Thomas Reid and 'The Way of Ideas', p. 19s.; Philip de Bary, Thomas Reid and Scepticism. His Reliabilist Response, p. 4-5; John Greco, How to Reid Moore, in: John Haldane and Stephen Read (eds.), The Philosophy of Thomas Reid - A Collection of Essays, p. 139ss.

${ }^{28} \mathrm{Cf}$. IHM I.i.12.
} 
presente na doutrina filosófica de George Turnbull, por certo tempo (17231726) regente do Marischal College, onde Reid obteve a sua formação em humanidades ${ }^{29}$. Em particular, Turnbull revelera profunda influência de Newton. Se, por mérito do seu método, o aperfeiçoamento da filosofia da natureza por Newton já estava consolidado, Turnbull acreditava em um progresso semelhante no que tange à filosofia moral. Em verdade, essa já era uma convicção de Newton, a saber, que através da filosofia natural poderia ser conhecida a "primeira causa", o seu "poder" sobre o mundo e os seus "benefícios", bem como o "dever" humano com respeito a Deus e aos demais. Assim, pois, Turnbull notara que tanto a "filosofia moral" como a "teologia natural" eram, segundo Newton, partes constituintes da "filosofia da natureza”. Nesse sentido, não só é o caso que o método aplicado por Newton servia àqueles domínios, mas também que eles, em particular a filosofia moral, são setores reais de investigação da "filosofia natural". Como indica BROADIE, o campo da filosofia moral diz respeito "à mente humana”, com suas faculdades, seus poderes, desejos e princípios de ação, e é um ramo da filosofia natural; nesse sentido, George Turnbull era, como filósofo moral e da mente, "newtoniano". 30

Brookes e Broadie confirmam que o "naturalismo providencial" comportava, em realidade, quatro proposições. Segundo a primeira, (a) as regulae são os meios para o sucesso na filosofia natural, que engloba não só as ciências naturais, mas também o estudo científico da mente humana,

\footnotetext{
${ }^{29}$ Em 1723, no Marischal College, Reid estudou por alguns meses sob George Turnbull. No decurso de um ciclo de preleções, Turnbull, entre outros temas, expôs o pensamento de Bacon, Descartes, Newton, Locke e Lorde Shaftesbury. Além disso, na sua obra Principles of Moral and Christian Philosophy, de 1740, George Turnbull apresentou diversas ideias associáveis a Thomas Reid, na sua obra futura. A influência de George Turnbull sobre Thomas Reid foi substantiva. Cf. Derek R. Brookes, Introduction, in: Thomas Reid, An Inquiry into the Human Mind on the Principles of Common Sense, p. xiv.; Alexander Campbell Fraser, Thomas Reid, p. 21ss. Sobre a formação de Reid em "filosofia da natureza", cf. Paul Wood, Thomas Reid and Culture of Science, in: Terence Cuneo and René Van Woudenberg (eds.), The Cambridge Companion to Thomas Reid, p. 57ss.

30 Para Turnbull, a parte moral do "grande projeto de filosofia natural" seria vista como a mais útil de todas, porque a investigação moral, se bem perseguida, produziria um saber para atingir a saúde da mente e protegê-la das corrupções de toda ordem. Algo parecido poderia ser lido em IHM I.i.11-12. Cf. Alexander Broadie, Reid in Context, in: Terence Cuneo and René Van Woudenberg (eds.), op. cit., p. 3839. Acerca de mestres e influências intelectuais sobre Reid, ligados à "pneumatologia" - estudo natural da mente em todos os domínios gerais de suas operações, como conhecimento, moral e gosto - do contexto escocês, cf. Charles Stewart-Robertson, Thomas Reid and Pneumatology. The Text of the old, The Tradition of the New, in: Melvin Dalgarno and Eric Matthews (eds.), The Philosophy of Thomas Reid, p. 390ss.
} 
buscando as suas operações e os seus princípios; ademais, (b) as "leis da natureza" são produto de "um ato providencial da vontade divina", tal que para explicá-las em definitivo nenhum outro princípio de explanação pode ser adicionado, ou seja, existem por terem sido ato do querer (pessoal) divino ${ }^{31}$. A (c) terceira proposição assevera que o propósito divino (o desígnio) pelo qual as leis da natureza foram criadas pode ser descoberto através do estudo das coisas que operam de acordo com as leis - em que o desígnio é, ao fim, uma propriedade do mundo e das partes do mundo, detectável sob as leis ou sob a ordem da natureza. Finalmente, a (d) quarta proposição do naturalismo providencial reza que as faculdades cognitivas humanas, parte da dispensação divina, têm uma função cientificamente determinável, uma vez que o conhecimento delas oferece certa percepção da mente de Deus, ao menos até o ponto em que se pode saber do propósito divino em criar as faculdades humanas - em que a direção do argumento parece ser do desígnio das faculdades ao desígnio da sua causa, isto é, ao Designador ${ }^{32}$. Assim, o estudo científico das faculdades cognitivas, morais e de gosto $^{33}$ revela que elas existem para serem mecanismos de formação de crenças verdadeiras, sobre o mundo exterior e mental, o sentido moral e o de beleza $^{34}$.

Para além dessas informações de fundo, a pesquisa nem sempre tem dado a justa atenção à necessidade de bem compreender o que, no intuito de realizar a "anatomia da mente" como cumprimento do método filosófico para o sistema mental, vale para Reid como o critério de observação e/ou experimento de fenômenos. Afinal, esse aspecto do método deve ser possível no que diz respeito à mente. Nesse caso, Reid, acabará por dizer que toda a filosofia é, primariamente, observação da mente e, secundariamente, é observação daquilo que, na linguagem e no comportamento, permite saber sobre a mente ${ }^{35}$. Dado que é o mental aquilo que se quer conhecer, então a

${ }^{31}$ Cf. Alexander Broadie, Reid in Context, in: Terence Cuneo and René Van Woudenberg (eds.), op. cit., p. 41-42; Derek R. Brookes, Introduction, in: Thomas Reid, op. cit., p. xiv.

${ }^{32}$ Sobre os itens (b), (c) e (d) em uma ótica reidiana, cf., por exemplo, Michael Pakaluk, A Defence of Scottish Common Sense, in: John Haldane and Stephen Read (eds.), The Philosophy of Thomas Reid A Collection of Essays, p. 155ss.

${ }^{33} \mathrm{O}$ senso comum, a propósito, apresenta princípios primeiros com respeito a esses três âmbitos; cf. EIP Vl.ii.426ss.

${ }^{34} \mathrm{Cf}$. Alexander Broadie, Reid in Context, in: Terence Cuneo and René Van Woudenberg (eds.), op. cit., p. 42-43.

35 Cf. EIP I.v.56ss. 
ênfase toda recai no que Reid chama de "atenção" às próprias operações mentais, e por essa atenção pode-se entender uma forma de "reflexão" ou voltar-se com a mente à própria mente - ou uma forma de introspecção. A filosofia precisa se fazer reflexiva, pois todos os seus assuntos se voltam ao mental ou o que só pode ser acessado por uma consciência introspectiva.

Em EIP, essa "atenção" - um acesso privilegiado à mente - é com frequência invocada naqueles Ensaios específicos sobre as operações $\operatorname{cognitivas}^{36}$. Assim, pois, no princípio do capítulo 5 do Ensaio II, dedicado à "percepção", Reid afirma que uma noção distinta sobre as operações pressupõe como condição necessária uma consciência delas, mas, mais ainda, requer uma atenção às mesmas "enquanto elas são exercidas", atenção essa seguida de reflexão "com cuidado", "enquanto elas são recentes e frescas em nossa memória" ${ }^{7}$. Assim, como atos, Reid distingue "consciência"38 e "atenção", e mesmo como poderes ou fontes de conhecimento - ainda que se pudesse argumentar que a "atenção" é uma subclasse de atos de consciência. Ademais, Reid, ao menos às vezes, parece distinguir "atenção" de "reflexão", embora proponha essas duas como operações necessárias para o conhecimento da mente. É visível que Reid quer chegar ao ponto em que a atenção à presença das operações e dos seus traços constitutivos e a reflexão sobre as mesmas, depois que aconteceram e, no entanto, permanecem vivas na memória, se tornam hábitos. Nesse caso, obtem-se o procedimento e o hábito que a própria escritura filosófica de Reid deixam ver concretizados no seu Inquiry e sobretudo nos seus Essays.

Um dos mais famosos desempenhos desse método de observação e raciocínio aplicado - em que, especulativamente, poder-se-ia dizer que a "atenção" está para a observação ou o experimento do evidente, ou seja, do claramente existente, e a "reflexão" está para o raciocínio que permitirá generalização necessária e adequada ou uma justa indução - é exatamente a conclusão de que, se atenção for dada aos atos da mente chamados de "percepção" de um objeto exterior aos sentidos, três características são sempre

\footnotetext{
${ }^{36}$ Cf., por exemplo, com variações terminológicas, EIP II.viii.118, 120.

${ }^{37}$ Cf. EIP II.v.96.

38 Cf. EIP I.v.58: "Essa reflexão deveria ser distinguida da consciência, com a qual ela é tão frequentemente confundida, mesmo pelo Sr. Locke. Todos os homens são conscientes das operações das suas próprias mentes, em todos os momentos enquanto estão despertos; mas, existem poucos que refletem sobre elas ou fazem delas os objetos do pensamento".
} 
encontradas ali, tal como seus "fenômenos", poder-se-ia dizer: "Primeiramente, alguma concepção ou noção do objeto percebido. Em segundo lugar, uma forte e irresistível convicção e crença da sua existência presente. E, em terceiro lugar, que essa convicção e crença são imediatas, e não [são] o efeito de raciocínio" ${ }^{39}$. Sob esse parâmetro, não seria a "reflexão" o meio pelo qual uma justa indução poderia ser realizada sobre a mente qua operação perceptual, de maneira que os princípios do senso comum seriam como que leis da natureza, ao mesmo tempo tomados por garantidos e descobertos ou descobríveis, no mesmo patamar de uma lei da natureza respectiva ao sistema material?

Mas, por certo, nenhum contexto sobre a importância desses passos metodológicos para a compreensão da mente e, portanto, para bem entender e defender o seu desempenho chamado "conhecimento" é mais claro, formalmente, do que os capítulos V-VI do Ensaio I ("Preliminar") - onde os capítulos são intitulados, respectivamente, "Dos meios próprios de conhecer as operações da mente" e "Da dificuldade de atentar para as operações das nossas próprias mentes”. A pesquisa ainda não deu a eles a merecida atenção, onde "atenção" mental é justamente um dos seus assuntos centrais. Além disso, esses capítulos preliminares são apresentados por Reid logo após a sua estrita recusa de procurar hipóteses para estabelecer crenças e o seu parecer suspeitoso sobre o raciocínio analógico ${ }^{40}$. Atenção-reflexão é, pois, o meio para saber da mente e de seus poderes.

Reid afirma, ali, que a fonte do conhecimento da mente é o que chama de "reflexão acurada sobre as operações das próprias mentes". E, antes mesmo de expôr sobre ela, ele parece fazer um favor ao leitor que puser a seguinte pergunta: atenção e reflexão não acabam por ser meios muito restritos, uma vez que cada indivíduo só pode conhecer a própria mente, e não as demais, de maneira que generalizações nomológicas sobre essa matéria ficariam, de princípio, obstaculizadas? Se essa pergunta - muito justa - fosse colocada, Reid poderia responder afirmando que há duas fontes que são "subservientes" àquela "reflexão acurada". A primeira é a "linguagem”, e a segunda é "a devida atenção ao curso das ações e da conduta humana" ${ }^{4}$. Em

\footnotetext{
${ }^{39}$ Cf. EIP II.v.96.

${ }^{40}$ Cf. EIP II.iii-iv. $47-55$.

${ }^{41}$ Cf. EIP I.v.56-57.
} 
realidade, o leitor cuidadoso e frequente da obra de Reid notará que ele respeita irrestritamente essas duas fontes subservientes.

A atenção à estrutura da linguagem se justifica para o propósito de pesquisa porque a linguagem é expressiva dos pensamentos e das operações da mente. Nesse caso, por "operações da mente" compreende-se "entendimento", "vontade" e "paixões", que, sendo comuns à humanidade, possuem "formas" ou "modos de discurso" ("forms of speech", "modes of speech") correspondentes em todas as línguas conhecidas. Segundo Reid, essas formas podem ser tomadas como "sinais" daqueles estados mentais e, portanto, expressam aqueles estados. Assim, pois, antes mesmo de explanar a atenção-reflexão que diretamente concerne à mente, Reid pede uma "atenção aos sinais", atitude essa que pode "dar considerável luz às coisas significadas por eles" ${ }^{2}$. Por esse aspecto, Reid quer dizer que o seguinte procedimento é justo: há, nas linguagens humanas, muitos "modos de discurso" (fato fonético e empiricamente constatável) pelos quais, por exemplo, os seres humanos significam estados mentais que são juízos - de recusa ou aceitação ou, então, que significam seus testemunhos ou profissões. $\mathrm{O}$ argumento tem a seguinte forma: dado que há precedência dos estados mentais com respeito aos fenômenos de fala, pode-se afirmar que, se operações mentais afins não fossem comuns à humanidade, não seria possível encontrar nas linguagens existentes "formas de discurso pelas quais elas são expressas" - formas de discurso, leia-se, semelhantes ${ }^{43}$.

Não se propõe uma correspondência perfeita entre mente e linguagem; por certo, o que pode haver na e ser distinguido através da mente humana é mais extenso do que aquilo que pode ser expresso e distinguido na linguagem "comum". Além disso, é claro que as linguagens têm peculiaridades, que não se verificam ou se repetem de forma genérica. Nesse sentido, a expectativa módica que se tem como respeito às linguagens em termos de estrutura é que elas revelem suficientemente as "distinções que toda a humanidade, nos negócios comuns da vida, tem ocasião de fazer”. Ou seja, o que é encontrado em comum nas linguagens, dada a dependência do linguístico para com o mental, "deve ter uma causa comum", e esse "comum" deve ser "devedor de uma noção ou percepção comum da mente humana”. Reid exemplifica essa

${ }^{42}$ Cf. EIP I.v.56.

${ }^{43}$ Cf. EIP I.v.56. 
dependência estrutural, que permite conclusões sobre o que é comum ao mental humano, com a lembrança de que as linguagens têm o plural em muitos substantivos. Disso, pode-se inferir que os seres humanos têm noções não só de coisas individuais, mas de atributos comuns a muitos indivíduos. Ou seja, a partir da estrutura correspondente entre mente e linguagem e do fato de a linguagem comportar o individual e o plural, pode-se concluir que a mente é capaz de concepções e percepções tanto da coisa individual quanto da coisa "universal"44. Não será demasiado afirmar, pois, que, em especial nos Essays, a teoria do senso comum de Reid - como esboço dos princípios de operação da mente enquanto poder cognitivo - está intimamente ligada à linguagem comum. Nos Essays, como anota OTERO, há cuidadosas análises linguísticas, tal que parte das mais importantes deduções de Reid repousam na referência a um uso adequado da linguagem ordinária ${ }^{45}$.

Em segundo lugar, que a "atenção ao curso das ações e da conduta humana" é outra fonte para informar-se sobre a mente, isso supõe a premissa de que as ações dos seres humanos podem ser tomadas como "efeitos" que têm, como causas, "sentimentos" (sentiments), "paixões" e "afecções”. Nesse caso, como em outros, Reid está convicto de que se pode julgar sobre a causa a partir do efeito. De forma semelhante à primeira fonte subserviente, a linguagem, entende-se que a passagem de comportamento comum a estado ou condição mental comum tem uma base empírica. Assim, pois, se o comportamento afetivo dos pais com respeito aos filhos é comumente observável (algo exterior ou perceptível), ele, então é "suficiente evidência" de "um afeto parental comum à humanidade" (algo interior ou mental) ${ }^{46}$. Assim, da conduta geral dos seres humanos é possível saber dos seus objetos naturais de estima e demais disposições ${ }^{47}$.

Em um sentido intermediário entre linguagem e conduta, mas sob a mesma marca de fonte subserviente acerca do mental, Reid fala também do

${ }^{44}$ Cf. EIP I.v.56-57.

${ }^{45} \mathrm{Cf}$. Ignacio Izuzquiza Otero, Thomas Reid y el conocimiento perceptivo como interpretación del mundo exterior, in: ProQuest Information and Learning Company (Consejo Superior de Investigaciones Cientificas), p. 30-31.

${ }^{46}$ Ainda assim, é controverso afirmar que a conexão que se faz entre linguagem e mente, bem como entre comportamento exterior e mente, para crer sobre os mais diversos estados mentais de outros possa ser uma conexão estabelecida indutivamente, pela experiência; Keith Lehrer, Reid on Evidence and Conception, in: Melvin Dalgarno and Eric Matthews (eds.), The Philosophy of Thomas Reid, p. 129130 , sugere que ela seja devida a um princípio inato, à constituição natural do ser humano.

${ }^{47}$ Cf. EIP I.v.57. 
bom caminho entre "opiniões" comumente observáveis (fato exterior perceptível) e estrutura da mente humana. Ora, as opiniões são efeitos dos poderes intelectuais da mente "como as suas ações são os efeitos dos seus princípios ativos" - e esse bom caminho, que chega ao fim em um entendimento da mente, poderia ter como primeiro termo as "préconcepções" e os "erros" comumente observáveis nos nível das opiniões: também esses revelariam um traço comum e estrutural da mente humana ${ }^{48}$. De forma interessante, essa luz sobre a estrutura mental-intelectual do ser humano, para o bem ou para o mal, é algo que, a partir das opiniões expressas comumente observáveis na própria história da filosofia, poderia ser atingida. Muitas e de diferentes qualidades são as opiniões filosóficas que surgiram entre os seres humanos - muitas falsidades e algumas verdades. Nesse labirinto, é possível encontrar o "ponto de vista que apresentou as coisas ao autor do sistema” - um fio vermelho que pode trazer alguma consistência e probabilidade ao que parece contraditório e maximamente imaginário (à luz de outros pareceres e sistemas) ${ }^{49}$.

Retomando a "reflexão" como fonte principal de informação sobre a mente, agora, na verdade, chamada de "reflexão atenta" sobre o objeto desse ato, a saber, as próprias "operações das nossas próprias mentes", o mental imediato, que só pode ser acessado se for termo de um estado de consciência, Reid lembra que as noções que se tem da mente e dos seus atos, a saber, da lembrança, do juízo, da vontade, etc., foram chamadas por Locke de "ideias de reflexão" - já entendida a "reflexão", por Locke, como um "poder de reflexão". Reid concorda com Locke que esse poder é uma forma de introspecção, com ela a mente vê "para dentro" e ali observa as suas "ações e operações”. De um modo, ainda seguindo a Locke, isso significa que o entendimento, não sem esforços, toma conhecimento de si, ou seja, o entendimento faz de si "o seu próprio objeto". A partir daí, Reid pode apresentar a sua própria definição do poder de "reflexão atenta":

"Este poder do entendimento, de fazer das suas próprias operações o seu objeto, de atentar para elas e examiná-las de

\footnotetext{
${ }^{48}$ Cf. EIP I.v.57.

${ }^{49}$ Cf. EIP I.v.57: "A história da filosofia, considerada como um mapa das operações intelectuais dos homens de gênio, deve sempre ser divertida, e pode às vezes nos dar visões do entendimento humano que não poderiam facilmente ser tidas de qualquer outro modo".
} 
todos os lados, é o poder de reflexão, pelo qual somente podemos ter qualquer noção distinta dos poderes da nossa própria [mente] ou de outras mentes" ${ }^{20}$.

Isso permite a Reid distinguir com sobeja clareza - como já apontado - "consciência" de "reflexão", o poder de fazer das operações e dos atos da mente "objetos do pensamento". Deve-se notar que a maioria das pessoas tem consciência de suas operações, sem atentar para elas. Educação e hábito levam ao seguinte quadro: consciência de atos e estados, porém atenção aos objetos exteriores, sobre os quais as operações são empregadas. Por isso, é possível que se tenha consciência de operações sem qualquer grau de atenção a elas. E a seguinte diferença ajuda a notar que Reid, aqui, tem mesmo em vista "reflexão atenta", conjugando o que, em outros textos, aparece separado, tendo em vista, contudo, um mesmo poder para obter conhecimento:

"A diferença entre consciência e reflexão é semelhante à diferença entre uma visão superficial de um objeto que se apresenta ao olho, enquanto estamos concentrados em alguma outra coisa, e aquele exame atento que damos a um objeto quando estamos totalmente dedicados em inspecionálo. A atenção é um ato voluntário; ela requer um empenho ativo para começá-lo e para continuá-lo; e ele pode ser continuado enquanto quisermos. Mas, a consciência é involuntária e de nenhuma continuidade, modificando-se com todo pensamento" 51 .

Se entendo bem, a reflexão implica, primeiramente, a concentração em algo - e isso seria a "atenção", em contraste com uma visão superficial de um objeto - e o exame atento de um objeto, em uma inspeção que conta com dedicação inteira. Assim, creio que "reflexão atenta" poderia ser equiparada a uma atenção continuada e intensa. Em segundo lugar, se a "reflexão atenta" é um "ato voluntário" desde o início até a continuação, a consciência é involuntária, não tem continuidade e muda conforme muda o estado mental. Dada a exigência dessas características, só seres humanos adultos, com certa

${ }^{50}$ Cf. EIP I.v.58.

${ }^{51}$ Cf. EIP I.v.59. 
maturidade, desdobram esse poder. O poder de reflexão atenta é melhorado pelo exercício. Seja como for, é só quando o hábito de atentar às operações mentais for conquistado que noções "claras e distintas" e "juízos” sobre elas podem ser ganhas e feitas. Dito em poucas palavras, "adquirir esse hábito é uma obra de tempo e labor" 52 .

Metodologicamente, pois, a reflexão atenta explica aquilo que Reid quer dizer com observação e justa indução como componentes das regras do filosofar, aqui, pois, quando se trata de investigar cientificamente o "sistema mental” - portanto, também o conhecimento humano. Reid se pôs, em seguida, a identificar (a) as causas por que o ser humano tem dificuldade de atentar para as operações da mente e ainda (b) os efeitos que surgiram a partir dessa dificuldade. Quanto às (a) causas, primeiramente "o número e a rápida sucessão das operações da mente tornam difícil dar a devida atenção a elas" - nenhuma sucessão na natureza parece mais rápida do que essa, e com elevada e constante mudança de cenário mental. Em segundo lugar, "nesse exercício, vamos na direção contrária aos hábitos que foram cedo adquiridos e confirmados por uma longa e invariada prática”. Tanto na infância quanto na fase adulta adquire-se o costume, auxiliado pelo contexto, de somente atentar "para os objetos dos sentidos", afastando a mente de "atentar para si mesma”. Em terceiro lugar, "as operações da mente, a partir da sua própria natureza, levam a mente a dar a sua atenção a algum outro objeto". Isso se deve ao fato de que, como revela a sensação (na qualidade de sinal natural) ligada às operações e como mostram as próprias operações da mente, elas têm objetos distintos desses atos. Ora, "enquanto somos levados por um forte impulso a atentar para o objeto”, operações e sensações escapam da notícia da mente. Em quarto lugar, quanto a esses dois tipos de atos, tão logo a mente dirige atenção ao objeto, a sensação ou a operação desvanece e, desse modo, escapa à notícia. Em quinto lugar, para descobrir a verdade sobre as operações da mente, não basta atentar para elas, mas é preciso também "distinguir acuradamente" as mínimas diferenças, "resolver e analisar operações complexas nos seus ingredientes simples" e, ainda, "desdobrar a ambiguidade de palavras" 53 . Nesse último passo, pois, Reid alerta para a

52 Cf. EIP I.v.59.

${ }^{53}$ Cf. EIP I.vi.59-61. 
necessidade de fazer exercícios exigentes, isto é, de ter de fazer distinções muito cuidadosas sobre o objeto do hábito.

Brevemente, os efeitos que surgiram a partir das cinco dificuldades podem ser resumidos ao dizer-se que o ramo da filosofia respectiva ao estudo do mental - que é a "pneumatologia" 54 - foi cultivado menos do que o devido, não atingiu o grau desejável de perfeição e está ainda na sua infância. Reid alude à "maturidade de uma ciência":

\begin{abstract}
"A maturidade de uma ciência pode ser julgada pelo seguinte: quando ela contém um sistema de princípios e conclusões deles tiradas, que são tão firmemente estabelecidos que, entre homens pensantes e inteligentes, não resta nenhuma dúvida ou disputa sobre eles, de maneira que aqueles que vêm depois podem erguer a superestrutura mais alto, mas jamais serão capazes de derrubar o que já está construído, no intuito de começar sobre um novo fundamento" 55 .
\end{abstract}

Em um exercício de aplicação, pode-se afirmar que a "geometria" se encontra, desde Euclides, na posição de um saber digno do nome de "ciência"; depois de cerca de dois mil anos no estágio infantil, a "filosofia da natureza" ganhou forma de ciência por Isaac Newton. Para Reid, a "filosofia da mente", com algum atraso, chegava também, na modernidade, a uma forma madura. Para ser alçada à categoria de ciência, ela precisa "ser purgada" de certas "hipóteses", que, a partir de autores da filosofia, levaramna a um "ceticismo completo". Ora, no fundamento da filosofia falsos princípios foram assumidos e, a partir daí, absurdidades foram concluídas, em especial a de que não existe nada do mundo material e exterior, que existem só ideias na mente, que essas têm somente existência no pensamento, que não há, na natureza, nem corpo nem mente, mas apenas ideais e impressões ${ }^{56}$. $\mathrm{Na}$ base dessas conclusões estão premissa hipotéticas sobre o conhecimento, como - assim pode-se repetir premissas mencionadas acima, na Introdução - "(1) Não podemos ter concepção de nada, mas só do que se parece com alguma sensação ou ideia na mente” e também “(1) Não

\footnotetext{
${ }^{54}$ Cf. EIP Prefácio, p. 12.

${ }^{55} \mathrm{Cf}$. EIP I.vi.62.

${ }^{56}$ Cf. EIP I.vi.63.
} 
podemos ter nenhum objeto imediato de pensamento senão as nossas próprias ideias”, etc. Como item do método científico e, derivativamente, do método filosófico científico de uma teoria do conhecimento, cabe ainda expor por que hipóteses não estabelecem nem desestabilizam crenças, indo ao encontro do único mecanismo positivo sobre como obter crenças com justificação: as regras do filosofar e os princípios do senso comum como boas leis do conhecer, que, enquanto são descobertas, são necessariamente ao mesmo tempo usadas.

\section{Conjeturas e racionalidade}

Muito cedo, Reid comparou “conjeturas" (ou "hipóteses”) a “criaturas dos homens" - invenções, com efeito - que adicionam para além da realidade e, assim, indevidamente somam às "criaturas de Deus", às "obras de Deus" 57 , ou seja, aos fatos da natureza.

No Ensaio I, "Preliminar", dos EIP, Reid dedica todo o Capítulo III às "hipóteses". Nele, Reid segue buscando os princípios, o fundamento e o método argumentativo da filosofia científica do conhecimento. De imediato, porém, é afirmado que um campo construído sobre "conjetura" não pode ser chamado de ciência. Conjetura pode produzir opinião, mas não pode produzir conhecimento (estrito) - a pergunta importante será se ela pode impedir conhecimento (estrito). Uma ciência só se constrói sobre fenômenos, aos quais se tem acesso "pela observação e pelo experimento" 58 . Reid não tem qualquer dúvida de que a filosofia - seja a da natureza ou a da mente -, em seu início ("os sistemas mais antigos") e por muito tempo consistiu essencialmente de conjeturas. Na maioria dos casos, sistemas de conjeturas mais engenhosos ganharam terreno sobre outros - em especial, por terem mais sucesso em explicar fenômenos comuns, mas não necessariamente por estarem solidificados por um método próprio e bem justificado ${ }^{59}$.

Reid, porém, não hesita em apontar para conjeturas no sistema de Descartes sobre os corpos celestes do sistema do mundo e, em outro domínio, sobre o assento da alma na glândula do cérebro chamada de "pineal”, especulando sobre como ela é afetada pelos sentidos e, em

${ }^{57}$ Cf. IHM I.i.12.

${ }^{58}$ Cf. EIP I.iii.47.

${ }^{59} \mathrm{Cf}$. EIP I.iii.47s. 
contrapartida, põe o corpo em movimento. Também assim ele supôs explicar os fenômenos da natureza, de forma plausível o suficiente para que recebesse a concordância do mundo erudito. Com ironia, Reid afirma que "hipóteses" casadas com "leves probabilidades" explicativas dos fenômenos chegaram a ganhar o estatuto de a "mais elevada realização de um filósofo"; ademais, ele indica o que acaba por recomendar uma hipótese à crença e a um sistema filosófico: o fato de ser (i) "bem ajustada", (ii) "embelezada por viva imaginação" e (iii) explicar "fenômenos comuns”. Em uma nota empírica, Reid tanto acredita que há inclinação em "homens de gênio" para inventar hipóteses como, em outros, há inclinação para crer que elas são o máximo mérito obtido em filosofia ${ }^{60}$. Os efeitos disso são, porém, graves para um ideal de saber.

Ora, (i) conjeturas são por natureza incertas. $\mathrm{O}$ assentimento a um enunciado deve ser proporcional à evidência - nesse caso, crer em conjeturas é um abuso intelectual porque é crer no que tem pequeno grau de probabilidade. Mais grave ainda é que, (ii) mesmo admitindo haver conjeturas prováveis que podem ser formadas sobre as "obras dos homens", as conjeturas formadas sobre as "obras de Deus" têm pouca probabilidade. Reid tem em vista a natureza, seja o sistema material ou o sistema mental. A situação, aqui, é de alguém que deseja compreender, por hipóteses, aquilo que foi feito por uma sabedoria super-excedente. Item dessa sabedoria, que recebe tratamento indireto no curso da exposição de Reid sobre a relação entre o sujeito percipiente e o mundo exterior ${ }^{61}$, é o modo como foi estabelecido que as "nossas mentes agem sobre os nossos corpos". Reid parece pensar em certas leis muito fundamentais sobre o funcionamento do mundo material e orgânico, acerca de cuja causa (eficiente e final), ao que parece, não se pode saber, desde o modo do curso dos planetas às funções do corpo humano ${ }^{62}$.

As passagens em EIP I.iii podem, no entanto, ser facilmente mal interpretadas nesse ponto. Thomas Reid não tem qualquer intenção de recusar a pesquisa bem guiada - científica - sobre a natureza criada por Deus, seja em que aspecto for. Antes, ele parece, em verdade, comparar a situação de conhecer as "obras de Deus" só por conjeturas àquela postura de alguém que,

\footnotetext{
${ }^{60} \mathrm{Cf}$. EIP I.iii.48s.

${ }^{61}$ Cf. EIP II.xiv.176-177.

${ }^{62}$ Cf. EIP I.iii.49.
} 
só por pensamentos, opiniões e hipóteses, busca conhecer essas obras. Sob esse aspecto, nenhum esforço ajudará a compreender a sabedoria divina. $\mathrm{O}$ único recurso de comprovado sucesso nesse empreendimento, tanto de sucesso de descoberta quanto de correção possível de um conteúdo em geral jamais bem refletido, é sempre de novo "observação paciente" e "experimentos acurados", ou ainda "conclusões tiradas por raciocínio estrito" a partir desses, o que, por outros contextos, presume-se ser apenas a indução. Isso revela conteúdos e confuta conjeturas:

"De todas as descobertas que foram feitas concernentes à
estrutura interna do corpo humano, jamais uma foi feito por
conjetura. Observações acuradas de anatomistas trouxeram à
luz inúmeros artifícios da natureza no planejamento dessa
máquina do corpo humano, os quais não podemos senão
admirar como excelentemente adaptados aos seus inúmeros
propósitos. Mas, o fisiologista mais sagaz jamais sonhou com
eles até que eles fossem descobertos. Por outro lado,
conjeturas inúmeras, formadas em diferentes épocas, com
respeito à estrutura do corpo, foram confutadas pela
observação, e nenhuma jamais foi confirmada"63.

Isso diz respeito a todas as partes das obras de Deus em que uma descoberta real foi feita. E a confutação generalizada de conjeturas e teorias hipotéticas, a partir daí, deveria ser aplicada a todos os ramos da filosofia: mostrar hipóteses, se não como "ridículas e infantis", pelo menos irreais por definição. Reid parece, pois, querer dizer que inteligência e gênio, por si, sendo a sabedoria humana inferior em proporção à sabedoria de Deus, jamais podem a priori tocar a sabedoria de Deus - como um caminho a priori, pela via dos pensamentos hipotéticos, para saber das obras divinas. $\mathrm{O}$ caminho da filosofia como saber científico, como dos outros ramos do saber, é - ao menos como parte sua integrante e significativa - o caminho da descoberta. O simples pensar ou idear, o simples produzir ou inventar da arte/técnica ou da própria razão, são habilidades insuficientes. Assim, conjeturas e teorias hipotéticas são virtudes insuficientes, podendo revelar o orgulho de pretender conhecer os "mistérios da natureza" só pelo próprio

${ }^{63}$ Cf. EIP I.iii.49. 
gênio. Que, com isso, Reid, para a filosofia, apela ao método da descoberta empírica, inclusive, a seguir nos Essays, no que tange o estatuto não-falacioso do conhecimento humano - em que cabe dizer de que modo os seres humanos conhecem e, na base disso, que eles de fato têm boas razões, forte evidência ou justificação para afirmar que conhecem -, isso pode ser atestado na seguinte passagem:

"Um homem erudito, em uma carta a Descartes, tem a
seguinte observação, que muito mereceu a atenção daquele
filósofo e de todos os que vêm depois dele. "Quando os
homens, sentados em seu gabinete e consultando somente os
seus livros, tentam discorrer sobre a natureza, eles podem de
fato dizer de que modo eles teriam feito o mundo, se Deus
tivesse dado a eles isso em incumbência; ou seja, eles podem
descrever quimeras, que correspondem à estupidez de suas
próprias mentes, não menos que a beleza admirável do
Universo corresponde à perfeição infinita do seu Criador;
mas, sem um entendimento verdadeiramente divino, eles
jamais podem formar tal ideia para si mesmos, como a
Deidade tinha, ao criar as coisas"”64.

Finalmente, embora Reid em alguns contextos pareça acreditar que, até um certo ponto, hipóteses não-naturais ou contradizentes ao desempenho natural das fontes de crença não são realmente capazes de anular crenças como condutas epistêmicas - nem de criar crenças - como adoção de posturas epistêmicas a modo de princípios e conclusões sobre o pensar ${ }^{65}$, há também contextos, na ciência do sistema material e mesmo do mental, em que hipóteses bem elaboradas levam os seres humanos a crenças hipotéticas. Porém, a (muito mais) natural e justificada ligação da crença com observação e indução, isto é, ao menos no horizonte do desempenho próprio da razão, levam Reid a afirmar que um sistema científico não deve, por lealdade à

${ }^{64} \mathrm{Cf}$. EIP I.iii.50.

${ }^{65}$ Creio que passagens de referência à atitude dos céticos podem ser arroladas aqui; cf., por exemplo, EIP II.v.51s. Nesse aspecto ao menos não me parece haver ambivalência na atitude de Reid com respeito a hipóteses, mesmo que ele admita, em contextos, o seu papel propulsor do crescimento do conhecimento científico, isto é, na sugestão de pesquisa empírica adicional, como nota Paul Wood, Reid on Hypotheses and the Ether, in: Melvin Dalgarno and Eric Matthews (eds.), The Philosophy of Thomas Reid, p. 438ss. 
mesma razão, adotar hipóteses, ainda que essas se fixassem na mente e imaginação humanas. Esse foi o exemplo de Newton, no que diz respeito à busca da causa da gravitação no sistema planetário. Mesmo que ele tenha se sentido tentado à hipótese, não pôs essa como princípio no qual crer provisoriamente ou a partir do qual construir teses posteriores:

\begin{abstract}
"Ouçamos o que ele diz: Rationem harum gravitatis proprietatum ex phaenomenis non potui deducere, et hypothesis non fingo. Quicquid enim ex phaenominis non deducitur hypothesis vocanda est. Et hypotheses, seu metaphysicae, seu physicae, seu qualitatum occultarum, seu mechanicae, in philosophia experimentali locum non habent" ["Eu ainda não fui capaz de deduzir a partir de fenômenos a razão para as propriedades da gravidade, e eu não fabrico hipóteses. Pois, tudo aquilo que não é deduzido a partir dos fenômenos deve ser chamado de uma hipótese; e hipóteses, sejam metafísicas ou físicas, ou baseadas em qualidades ocultas, ou mecânicas, não têm nenhum lugar na filosofia experimental" $]^{66}$.
\end{abstract}

A partir dos três momentos de exposição do método e de aspectos da natureza da filosofia como domínio científico do sistema mental - em descrição ${ }^{67} e$ argumentação a modo de construção de teorias específicas sobre seus conceitos e interesses maiores -, cabe anotar brevemente certas consequências para a crítica à "teoria comum das ideias"

\title{
Considerações finais
}

Alguns apontamentos conclusivos podem ser feitos sobre (i) as regras do filosofar, (ii) a anatomia da mente e (iii) conjeturas e racionalidade, em especial no que concerne ao escopo de aplicação desses itens. De início, notese de que modo os passos (i) e (ii) são relevantemente aplicados para desaprovar a teoria das ideias: ela é sumamente desaprovada pelo recurso às regulae philosophandi e à anatomia da mente. Em diversas passagens, Reid

\footnotetext{
${ }^{66} \mathrm{Cf}$. EIP I.iii.51-52. Sobre o papel das hipóteses físicas no pensamento de Newton, cf., por exemplo, Ivo Schneider, Isaac Newton, p. 94-99.

${ }^{67}$ Sem dúvida, esse aspecto aparece com maior destaque no presente estudo.
} 
insiste na não existência das ideias ${ }^{68}$, em que isso significa que não encontra evidência para tratar ideias como itens distintos dos atos ou das operações da mente, em uma suposta condição de objetos dos atos ou das operações - de percepção, memória, etc. ${ }^{69}$. Assim, por exemplo, no caso da percepção, a reflexão mostra que perceber envolve crer no objeto exterior imediato existente e, em nenhum aspecto descritível, na ideia do objeto exterior ${ }^{70} \mathrm{Na}$ mente, nada mostra que a ideia existe como meio representativo, mas os atos e as operações mentais no papel mesmo de significar ${ }^{71}$.

Assim, é natural que, se "ideias" significam, antes, os próprios atos mentais ou as próprias operações mentais, em seus diversos tipos - ou então as "sensações" como tipo de ato/operação mental sem objeto próprio -, elas existem evidentemente. A recusa de Reid consiste em não conceder a elas caráter de fenômeno observado ou experimentado, na base de cuja evidência uma generalização sobre o conteúdo objetivo ou formal dos atos mentais possa ser feito, ali onde são entendidas como reza a "teoria comum das ideias", a saber, como distintas dos atos ou das operações mentais e, enfim, como os "objetos imediatos" dos atos ou das operações mentais ${ }^{72}$. Nesse sentido, a título de exemplo, um ato como o de perceber teria estrutura quatripartite: o poder ou sujeito que pensa, o pensamento, a ideia (objeto imediato) e o objeto exterior (objeto mediato) ${ }^{73}$. O poder de atentar aos estados mentais e refletir, porém, nunca revela esse último quadro. Antes, revela um quadro tripartite, de novo considerando apenas os atos de percepção: o poder ou sujeito que percebe, a crença existencial imediata (o ato de perceber) e o objeto exterior imediato ${ }^{74}$. É a existência desses traços que o fenômeno experimentado de perceber, em um caso particular, mostra com evidência diante do poder de refletir ${ }^{75}$.

${ }^{68}$ Cf. EIP II.iv.93; II.viii.126; Il.xiv.171, 172ss.

${ }^{69}$ Cf. John Greco, Reid's Reply to the Skeptic, in: Terence Cuneo and René Van Woudenberg (eds.), op. cit., p. 138.

${ }^{70}$ Cf. EIP II.vi.97-99; II.xiv.172-174.

${ }^{71}$ Cf. EIP II.ix.135ss.; EIP II.xiv.171s.

${ }^{72}$ Cf. EIP. Il.x.136s.

${ }^{73}$ Cf. EIP II.xiv.171ss. Cf. também John Greco, Reid's Reply to the Skeptic, in: Terence Cuneo and René Van Woudenberg (eds.), op. cit., p. 140.

${ }^{74}$ Como é bem conhecido, é claro que a descrição do ato de perceber em si e enquanto tal revelaria outra estrutura tripartite de componentes: noção, convicção de existência e imediaticidade; cf. EIP II.vi.96-101.

${ }^{75}$ Cf. EIP II.ix.132; II.x.136. 
Sendo então lembrado que a segunda regra do filosofar requer que a causa de um efeito seja observada e, nesse patamar de desempenho, trazida ao estatuto de lei da natureza - nesse caso, do sistema mental ou imaterial -, Reid também alega que, mesmo se ideias, como na "teoria comum", existissem, elas não seriam capazes de explicar o que supostamente explicam, a saber, que e como conhece-se os objetos mediatos do pensar. Elas não tornam bem entendidas as "operações da mente"76. Reid nota que, ao reduzir toda operação mental a um só tipo de fenômeno, a "percepção" imediata das ideias como meios representativos e assim também a "memória" e a "imaginação" imediata das "ideias" são uma só operação em termos de tipo. Já é um fato grave que nada permite compreender o poder de "perceber" ideias imediatamente, ou seja, como coisas presentes em contato contínguo com o sujeito percipiente, implicando essa contiguidade um tipo de "sentimento" (feeling). Nesse sentido, é correto dizer que, sob a suposição de que as ideias de fato existem nas ditas operações, nada pode ser explicado, porque, como visto, um poder explanatório depende da condição de existência evidente, e a suposição em jogo não tem nenhum conteúdo descritivo. O investigador se encontra "perdido" no que diz respeito à possibilidade de uma "percepção imediata" das ideias ${ }^{77}$.

E, ao final, nada explica como, além das sensações ou ideias, seja possível perceber objetos externos quando se os percebe, como seja possível lembrar coisas passadas quando se as lembra, como seja possível imaginar algo fictício quando se o imagina. Qual é a dificuldade aqui? A dificuldade é que, nesses relatos, pressupõe-se uma continguidade a modo de "toque" entre coisa percebida, lembrada ou imaginada e ideia na mente, e em seguida entre ideia na mente e sujeito cognoscente. Porém, "contato" entre duas coisas como mundo material e mente não requer nenhum "sentimento" de tangência, e a "conexão entre contiguidade e percepção" é inexplicável, pois ela se baseia em uma suposta e mal fundada "semelhança entre mente e corpo"78 (cf. abaixo). Além de tudo isso, parece-me correto afirmar que Reid, em diversas passagens, anota um outro aspecto que mostra a insuficiência das

\footnotetext{
${ }^{76}$ Cf. EIP II.xiv.184s.

${ }^{77}$ Cf. EIP II.xiv.185. Cf. também John Greco, Reid's Reply to the Skeptic, in: Terence Cuneo and René Van Woudenberg (eds.), op. cit., p. 141.

${ }^{78}$ Cf. EIP II.xiv.185. Sobre os pontos discutidos nessas considerações finais, cf. Nicholas Wolterstorff, Thomas Reid and the Story of Epistemology, p. 45-76.
} 
ideias para explicar como se conhece o que se conhece a partir delas, a saber, o seu objeto ou sua causa formal, a cada vez. Ora, nada na "observação" das mesmas, se existissem, sugeriria a que se devem elas como "ideias" ou "sensações" de tal e tal tipo. Ou seja, o que garante, nas próprias "ideias" envolvidas na percepção, por exemplo, que elas são intencionais dessa e não de outra forma e têm, portanto, evidentemente dívida formal com objetos do mundo exterior? ${ }^{79}$

Finalmente, (iii) conjeturas são sumamente rejeitadas para que qualquer parecer sobre a relação entre mente e corpo, entre sistema mental e sistema material, possa ser cientificamente oferecido. Assim, no capítulo "Reflexões sobre a teoria comum das ideias" (EIP II.xiv), Reid estabelece com detalhes, na segunda reflexão, que autores em filosofia geralmente tomaram a existência das ideias por garantida e de tal modo que não poderia ser posta em questão. Em seguida, Reid se dedica a discutir se, quando objetos são percebidos, eles "agem sobre nós, ou nós agimos sobre eles". Reid afirma que nada nesse último discurso é evidente e que para nada disso achou prova. Ora, dizer que uma coisa age sobre outra é dizer que um poder é exercido por um agente, que gera mudança na coisa que sofre a ação. Nesse significado preciso, não há por que asserir que, na percepção, “o objeto age sobre a mente, ou a mente [age] sobre o objeto" 80 .

Um objeto percebido ou mesmo a impressão física consequente jamais age - a título de causa eficiente - sobre a mente no sentido de mudá-la: "ser percebido", para um objeto que efetua uma impressão sensória dada a constituição cognitiva humana - é uma "denominação externa"81. A inclinação de dizer que a percepção se deve a uma ação do objeto sobre a mente se remete ao costume de formar "noções da mente" a partir de uma semelhança admitida entre ela e o corpo - assim, toma-se que o pensarperceber na mente é análogo ao movimento dos corpos, em que um sofre ação de outro corpo ao ser tocado por ele em um caso de contiguidade. Mas, a mente não percebe a partir de um impulso ou toque do objeto. Raciocínios a partir dessas analogias são errôneos: impõem à mente medidas e qualidades dos $\operatorname{corpos}^{82}$. Na percepção, tampouco a mente age sobre o objeto. Perceber

\footnotetext{
${ }^{79}$ Cf. EIP II.viii.126; II.ix.134s.; II.x.138s.

${ }^{80}$ Cf. EIP.II.xiv.184. Cf. sobre isso, entre outros, Keith Lehrer, Thomas Reid, p. 97s., 99s.

81 Cf. Keith Lehrer, op. cit., p. 98s.

${ }^{82}$ Cf. EIP II.xiv.176-177.
} 
um objeto e agir sobre ele são coisas totalmente diferentes. Atos mentais são sempre "imanentes", e não "transitivos" efeito sobre qualquer objeto exterior”. Assim, não há evidência de uma ação da mente, na percepção, sobre o objeto ${ }^{84}$. Novamente, Reid insiste em dizer que o erro aqui implícito, de que há relação entre mente e mundo somente se há continguidade entre objeto percebido e sujeito percipiente, é uma préconcepção oriunda de analogia. Há uma contiguidade entre o objeto e o órgão sensório, tal que essa "impressão" supõe, sim, contiguidade. Por analogia, é-se levado a crer algo similar quanto à relação entre objeto e mente em uma operação tal como a percepção - o "tato" muito influenciou a própria linguagem sobre as operações da mente, sugerindo ainda mais a continguidade entre o que causa a impressão e o que a recebe, entre o que é sentido e aquele que sente. Esse raciocínio, ainda que enganoso ${ }^{85}$, tem, sim, poderosa influência sobre o juízo ${ }^{86}$.

Pondo de lado analogias e refletindo corretamente sobre a percepção de objetos sensórios, o correto é dizer que, apesar da consciência do ato de perceber, tem-se total ignorância sobre como a percepção é produzida - sobre $o$ como da percepção sabe-se tão pouco quanto sobre como, de maneira definitiva (e progressos da ciência a parte), os seres humanos foram feitos. Houvesse uma imagem/ideia na mente, contígua a ela, e isso não passa de mera conjetura, tão pouco se saberia sobre como a imagem causa a percepção quanto pouco se sabe sobre como um objeto distante a causa. A teoria toda, pois, das ideias, nesse tocante, nem é fundada em evidência e nem explica qualquer fenômeno da percepção - como imagems imediatas contíguas ou,

\footnotetext{
${ }^{83}$ Cf. também EIP IV.1.300.

${ }^{84} \mathrm{Cf}$. EIP II.xiv.177. Provisoriamente, creio que há duas teses sobre a natureza da mente, que não podem ser exploradas aqui, que ajudariam a bem fundamentar o raciocínio de Reid. A primeira reza: "O mental é aquilo que só pode ser termo de uma consciência" - tese que não implica que a mente só conhece o que é mental. A outra tese é "O mental como tal não pode ser causado (gerado ou modificado) pelo material".

${ }^{85}$ Esse seria um caso em que a desproporção nas coisas comparadas - corpo e corpo, corpo e mente é tão grande que a analogia não trará índices satisfatórios de probabilidade. Cf. I.iv.53-54, aqui especialmente p. 54: "Mas, todos os argumentos tirados de analogia são ainda mais fracos quanto maior for a disparidade que há entre as coisas comparadas; e portanto, devem ser os mais fracos de todos quando comparamos corpo e mente, porque não existem duas coisas mais dessemelhantes na natureza".

${ }^{86}$ Cf. EIP II.xiv.177-178; IV.ii.312ss.
} 
ao fim, objetos mediatos podem ser percebidos ${ }^{87}$. Mais adiante, no mesmo capítulo, isso é reiterado:

\begin{abstract}
"Alguns filósofos fizeram o esforço de fazer com que todos os nossos sentidos fossem somente diferentes modificações do tato, uma teoria que serve somente para confundir coisas que são diferentes, e de confundir e obscurecer coisas que são claras. A teoria das ideias se assemelha a isso, ao reduzir todas as operações do entendimento humano à percepção de ideias em nossas próprias mentes. Esse poder de perceber ideias é tão inexplicável quanto qualquer dos poderes explicados por ele. E a contiguidade do objeto não contribui absolutamente em nada para torná-lo melhor entendido, porque não se manifesta nenhuma conexão entre contiguidade e percepção, a não ser o que está fundado em pré-concepções, tiradas de alguma semelhança imaginada entre a mente e o corpo, e a partir da suposição de que, na percepção, o objeto age sobre a mente, ou a mente sobre o objeto. Vimos de que modo essa teoria levou os Filósofos a confundir aquelas operações da mente, as quais a experiência ensina a todos os homens que são diferentes e ensina-lhes a distinguir na linguagem comum; e [vimos] que ela os levou a inventar uma linguagem inconsistente com os princípios sobre os quais todas as linguagens estão fundadas" 88 .
\end{abstract}

A meu juízo, Keith Lehrer apontou com correção que, segundo Reid, há uma lei da natureza, cuja explicação não é conhecida e é eventualmente incognoscível agora, pela qual as impressões físicas ocasionadas pelos objetos - e, pois, via órgões sensórios, nervos e cérebro - são "conjugadas regularmente com a percepção". No sentido de "dar ocasião", pode-se dizer que objetos e impressões "causam" as percepções. Nesse caso, "conjunção regular", expressão mesma de "lei da natureza", suplementa "causação". O quadro (dualista) buscado por Reid é o de que a impressão sobre o órgão sensório seja tomada pelo agente das operações da mente como "instrumento" ou "ocasião" para perceber; porém, nem as impressões nem a

87 Cf. EIP II.xiv.177-178.

${ }^{88}$ Cf. EIP II.xiv. 185. 
sua conjunção regular com percepções são entendidas como necessárias. Essencial para a perceção é o poder para tanto; perceber é na sua essência causação interna, não a partir das impressões sensórias e dos objetos ${ }^{89}$.

${ }^{89}$ Cf. Keith Lehrer, op. cit., p. 98-99. Sem dúvida, é uma questão espinhosa se Reid é bem sucedido, e suficientemente detalhado, no que tange à aplicação de sua versão das regras newtonianas do filosofar ao tópico da relação matéria e mente - e, pois, à defesa do papel ativo único da mente imaterial, na percepção. Cf. sobre isso Alan Tapper, Reid and Priestley on Method and the Mind, in: John Haldane and Stephen Reid (eds.), op. cit., p. 104ss., 109ss., que expõe o problema na perspectiva da disputa de Reid com o materialismo de Joseph Priestley e da tese da passividade da matéria. Fontes sobre a disputa de Reid com o materialismo de Priestley são também, é claro, Paul Wood, Introduction, in: Paul Wood (ed.), Thomas Reid on the Animate Creation - Papers Relating to the Life Sciences, p. 30-56, e Thomas Reid, Part Three - Materialism (Papers), in: Paul Wood (ed.), Thomas Reid on the Animate Creation - Papers Relating to the Life Sciences, p. 125-241. 


\section{Referências}

\section{Fontes}

REID, T. An Inquiry into the Human Mind on the Principles of Common Sense (1764). In: BROOKES, D. R. (ed.). Thomas Reid - An Inquiry into the Human Mind on the Principles of Common Sense. A critical edition. Edinburgh: Edinburgh University Press, 2000 (paperback).

. Essays on the Intellectual Powers of Man (1785). In: BROOKES, D. R. Thomas Reid - Essays on the intellectual powers of man. A critical edition - The Edinburgh Edition of Thomas Reid. Annotations by Derek R. Brookes and Knud Haakonssen. Introduction by Knud Haakonssen. Pennsylvania: Pensylvannia State University Press, 2002.

. Part Three - Materialism (Papers). In: WOOD, P. (ed.). Thomas Reid on the Animate Creation - Papers Relating to the Life Sciences. University Park (Pennsylvania): The Pennsylvania State University Press, 1995, p. 125-241.

The Philosophical Orations of Thomas Reid. Delivered at Graduation Ceremonies in King's College, Aberdeen, 1753, 1756, 1759, 1762. Edited with Introduction and Bibliography by D. D. Todd. Translated from the Latin by Shirley Darcus Sullivan. Carbondale and Edwardsville: Southern Illinois University Press (The Journal of the History of Philsophy Monograph Series), 1989, p. 31-78.

\section{Literatura secundária}

BARY, P. de. Thomas Reid and Scepticism. His Reliabilist Response. London - New York: Routledge, 2002.

BROADIE, A. "Reid in Context". In: CUNEO, Terence and VAN WOUDENBERG, René (eds.). The Cambridge Companion to Thomas Reid. Cambridge: Cambridge University Press, 2004, p. 31-52.

BROOKES, D. R. "Explanatory Notes”. In: REID, THOMAS. An Inquiry into the Human Mind on the Principles of Common Sense. A critical edition. Edited by Derek R. Brookes. Edinburgh: Edinburgh University Press, 2000 (paperback), p. 219234.

. "Introduction". In: REID, THOMAS. An Inquiry into the Human Mind on the Principles of Common Sense. A critical edition. Edited by Derek R. Brookes. Edinburgh: Edinburgh University Press, 2000 (paperback), p. xi-xxv. 
FRASER, A. C. Thomas Reid. Edinburgh - London: Oliphant Anderson \& Ferrier (Famous Scots Series), 1898 (repr.).

GALLIE, R. Thomas Reid and 'The Way of Ideas'. Dordrecht - Boston - London: Kluwer Academic Publishers, 1989.

GRECO, J. "How to Reid Moore". In: HALDANE, J. and READ, S. (eds.). The Philosophy of Thomas Reid - A Collection of Essays. Oxford: Blackwell Publishing, 2003, p. 131-150.

. "Reid's Reply to the Skeptic". In: CUNEO, T. and VAN WOUDENBERG, R. (eds.). The Cambridge Companion to Thomas Reid. Cambridge, Cambridge University Press, 2004, p. 134-155.

LEHRER, K. "Reid on Evidence and Conception". In: DALGARNO, M. and MATTHEWS, E. (eds.). The Philosophy of Thomas Reid. Dordrecht: Kluwer Academic Publishers, 1989, p. 121-144.

. Thomas Reid. London - New York: Routledge (The Arguments of the Philosophers), 1989.

MICHAUD, Y. "Reid's Attack on the Theory of Ideas: From a Reconsideration of Reid's Arguments to a Reassessment of the Theory of Ideas”. In: DALGARNO, M. and MATTHEWS, E. (eds.). The Philosophy of Thomas Reid. Dordrecht: Kluwer Academic Publishers, 1989, p. 9-34.

OTERO, I. I. "Thomas Reid y el conocimiento perceptivo como interpretación del mundo exterior". In: ProQuest Information and Learning Company (Consejo Superior de Investigaciones Cientificas), (2005), p. 21-41.

PAKALUK, M. "A Defence of Scottish Common Sense". In: HALDANE, J. and READ, S. (eds.). The Philosophy of Thomas Reid - A Collection of Essays. Oxford: Blackwell Publishing, 2003, p. 151-168.

RYSIEW, P. "Reid and Epistemic Naturalism". In: HALDANE, J. and READ, S. (eds.). The Philosophy of Thomas Reid - A Collection of Essays. Oxford: Blackwell Publishing, 2003, p. 24-43.

SCHNEIDER, I. Isaac Newton. München: C. H. Beck, 1988.

STEWART-ROBERTSON, C. "Thomas Reid and Pneumatology. The Text of the old, The Tradition of the New". In: DALGARNO, M. and MATTHEWS, E. (eds.). The Philosophy of Thomas Reid. Dordrecht: Kluwer Academic Publishers, 1989, p. 389411.

TAPPER, A. "Reid and Priestley on Method and the Mind". In: HALDANE, J. and READ, S. (eds.). The Philosophy of Thomas Reid - A Collection of Essays. Oxford: Blackwell Publishing, 2003, p. 98-112. 
TODD, D. D. "Introduction". In: REID, Thomas. The Philosophical Orations of Thomas Reid. Delivered at Graduation Ceremonies in King's College, Aberdeen, 1753, 1756, 1759, 1762. Edited with Introduction and Bibliography by D. D. Todd. Translated from the Latin by Shirley Darcus Sullivan. Carbondale and Edwardsville: Southern Illinois University Press (The Journal of the History of Philsophy Monograph Series), 1989, p. 1-28.

VAN WOUDENBERG, R. "Reid and Kant against the Sceptic". In: HOUSTON, J. (ed.). Thomas Reid. Context, Influenxe and Significance. Edinburgh: Dunedin Academic Press, 2004, p. 161-186.

WOLTERSTORFF, N. "Reid on Common Sense". In: CUNEO, T. and VAN WOUDENBERG, R. (eds.). The Cambridge Companion to Thomas Reid. Cambridge: Cambridge University Press, 2004, p. 77-100.

Thomas Reid and the story of epistemology. Cambridge: Cambridge University Press, 2001.

WOOD, P. "Introduction”. In: WOOD, P. (ed.). Thomas Reid on the Animate Creation - Papers Relating to the Life Sciences. University Park (Pennsylvania): The Pennsylvania State University Press, 1995, p. 1-78.

"Reid on Hypotheses and the Ether". In: DALGARNO, M. and MATTHEWS, E. (eds.). The Philosophy of Thomas Reid. Dordrecht: Kluwer Academic Publishers, 1989, p. 433-446.

. "Thomas Reid and Culture of Science". In: CUNEO, T. and VAN WOUDENBERG, R. (eds.). The Cambridge Companion to Thomas Reid. Cambridge: Cambridge University Press, 2004, p. 53-76.

Email: roberto.pich@pucrs.br

Recebido em: Novembro/2010

Aprovado em: Dezembro/2010 